\title{
HEALING OF PERIAPICAL LESION IN TEETH OBTURATED WITH DIFFERENT TECHNIQUES AND LENGTHS (RADIOGRAPHIC ASSESSMENT)
}

\author{
Abd Elsaber NR*, Fayyad DM* and Abd Elgawad RA*
}

\begin{abstract}
Aim: The purpose of this study was to assess healing of periapical lesion in either symptomatic or asymptomatic cases after obturation with different obturation techniques: cold lateral compaction and single cone obturation techniques at different apical extensions; $1 \mathrm{~mm} \& 2 \mathrm{~mm}$.

Materials and Methods: A total of eighty patients were divided into two main groups; symptomatic or asymptomatic $(n=40)$ then each group was subdivided into two subgroups $(n=20)$ according to the obturation technique; subgroup a: Cold lateral compaction technique and subgroup b: single cone obturation technique. Further, each subgroup was divided into two divisions $(\mathrm{n}=10)$ depending on whether the apical extent; 1 or $2 \mathrm{~mm}$ from radiographic apex. All cases were prepared and obturated. CBCT scans were taken preoperatively, at 3,6, and nine months and volume of the lesion was calculated to determine the treatment outcome. Data were then gathered, tabulated and statistically analyzed.
\end{abstract}

Results: At $1 \mathrm{~mm}$, no significant difference between mean $\%$ changes in lesion volume after using lateral compaction or single cone techniques either asymptomatic or symptomatic along the evaluation periods while at $2 \mathrm{~mm}$ lateral compaction technique showed higher mean $\%$ decrease in lesion volume than single cone technique after 3,6 as well as 9 months. In both groups, using lateral compaction technique, no significant difference was recorded at 1 or $2 \mathrm{~mm}$ apical extension of filling while in single cone, at $1 \mathrm{~mm}$ apical extension revealed higher decrease in lesion volume than $2 \mathrm{~mm}$

Conclusions: Radiographic success rate of the single cone obturation technique was comparable with those of the lateral compaction obturation technique in root canal treatment of teeth with periapical lesions in short term evaluations at $1 \mathrm{~mm}$ apical extension.

KEYWORDS: Lateral compaction, Single cone, periapical lesion, CBCT.

* Department of Endodontics, Faculty of Dentistry, Suez Canal University, Ismailia, Egypt 


\section{INTRODUCTION}

Periapical lesion caused by etiological factors of endodontic origin has an influence on the outcome of root canal treatment, its detection and characterization represents an important pre-operative prognostic factor ${ }^{(\mathbf{1})}$. The role of bacteria and the complex anatomy of the apical third canal in the development, persistence of apical periodontitis in addition to their direct relation to postoperative pain are well established $^{(2)}$. Mechanical instrumentation and the use of antimicrobial irrigating solutions are mainly aiming to reduce the intracanal microbial load to prevent or treat periapical tissues inflammation ${ }^{(3)}$ But, Surviving microorganisms following instrumentation and irrigation is prime player affecting the outcome of endodontic treatment; so the need to entomb the remaining resistant bacteria inside the canals and prevent the influx of tissue fluids inside the canal is mandatory. This is mainly achieved by proper obturation to permit healing of periapical lesion ${ }^{(4)}$ Both clinical and radiographic findings were used to determine healing outcome of periapical lesion ${ }^{(5)}$. These outcome of endodontic treatment of teeth with apical periodontitis of are widely affected by several factors; selected treatment plan which includes (single vs. multiple visits treatment), chemomechanical preparation, technique and length of obturation, ${ }^{(6)}$. The purpose of this study was to: compare radiographically the effect of different obturation techniques on the healing of periapical lesions: cold lateral compaction and single cone obturation techniques in either symptomatic or asymptomatic cases with periapical lesions. Moreover, investigate the influence of apical extent of root canal filling on the treatment outcome in teeth with periapical lesions at: $1 \& 2 \mathrm{~mm}$.

\section{MATERIALS AND METHODS}

The research was approved by the Ethics Committee of Faculty of Dentistry, Suez Canal University. A total of eighty patients were enrolled in this study, Oral and written informed consents were obtained from all participants and they informed about the aim \& design of the investigation and follow-up periods. Preoperative radiographic assessment was performed through CBCT using Scanora 3D CBCT (Soredex, Tuusula, Finland). The CBCT scans were imported into the OnDemand3D software and the analyses were performed to calculate preoperative volume of the lesion to determine the baseline record to which the treatment outcome was evaluated (Figure 1).

The eighty cases were divided into two main groups ( $n=40)$ according to the presence or absence of signs and symptoms. Chemomechanical preparation was performed using Revo $\mathrm{S}$ rotary Files up to AS40 (Micro Mega, Besancon Cedex, France) in crown-down manner utilizing X-Smart Plus Endomotor (Dentsplyserona Maillefer, Ballaigues, Switzerland). $\mathrm{NaOCl} 2.5 \%$ was used as an irrigant in all cases after every time of file insertion with
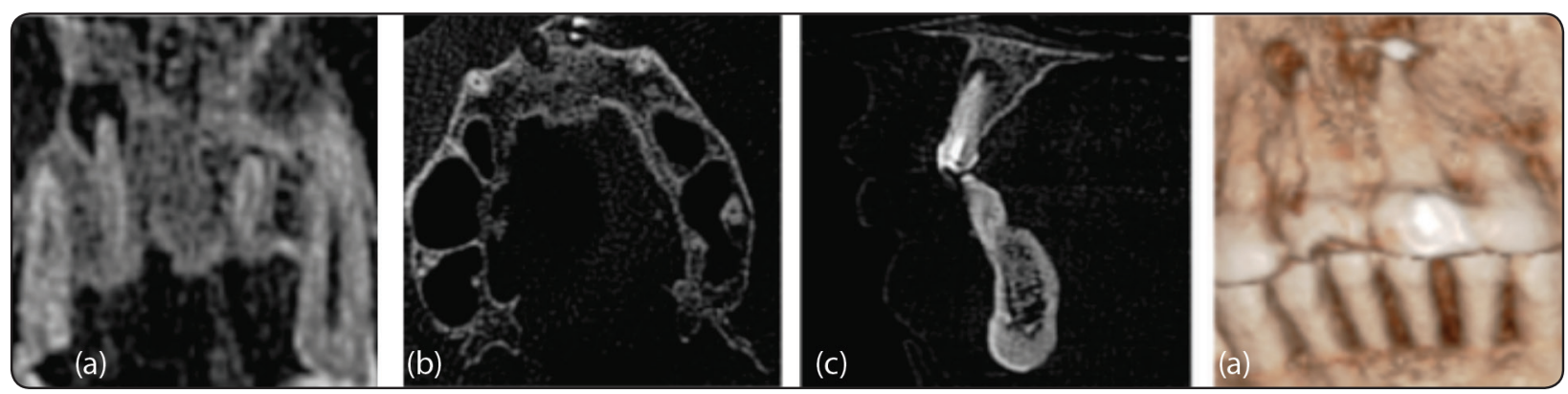

Fig. (1) CBCT scans showing preoperative periapical lesion in: a- coronal view, b- axial view, c- sagittal view and $3 \mathrm{D}$ reconstruction view 
a total volume of $15 \mathrm{ml}$ per each sample using a 30-gauge side-vented irrigation needle (DiaDent Group, Yeonije, LTD, South Korea). Each group was subdivided into two subgroups $(\mathrm{n}=20)$ according to the obturation technique; subgroup a: Cold lateral compaction technique and subgroup b: single cone obturation technique. Further, each subgroup was divided into two divisions $(\mathrm{n}=10)$ depending on whether the apical extent $1 \mathrm{~mm}$ or $2 \mathrm{~mm}$ from radiographic apex. Obturation was carried out using Gutta percha with taper $2 \%$ and $6 \%$ according to each subgroup respectively mixed Epoxy resin based sealer AD SEAL (Meta Biomed CO, LTD, South Korea ). Postoperative CBCT scans of the cases were taken in the same way as previously mentioned at follow-up intervals; three, six, and nine months. Volume of the lesion was calculated via segmentation procedures to determine the treatment outcome.

\section{Statistical Analysis}

Data were presented as mean, median, standard deviation (SD), minimum, maximum and 95\% Confidence Interval (95\% CI) values.Mann-Whitney $\mathrm{U}$ test was used to compare between asymptomatic and symptomatic cases, the two obturation techniques as well as the two lengths of root canal obturation. Friedman's test was used to study the changes by time in each group. The significance level was set at $P \leq 0.05$. For both symptomatic or asymptomatic groups, our investigations revealed no statistically significant difference between mean value of \% changes in lesion volume between the two obturation techniques at $1 \mathrm{~mm}$ apical extension of root canal filling using lateral compaction or single cone techniques through the whole study periods. On the other hand, at $2 \mathrm{~mm}$ apical extension of root canal filling, lateral compaction technique showed higher mean \% decrease in lesion volume than single cone technique after 3, 6 as well as 9 months. Regarding the finding of apical extension of root canal filling, in both symptomatic and asymptomatic cases obturated using lateral compaction technique, statistical analysis revealed no statistically significant difference between mean $\%$ changes in lesion volume with 1 or $2 \mathrm{~mm}$ apical extension of root canal filling through the whole evaluation periods $(\mathrm{P}>0.05)$. However, cases obturated with single cone technique at $1 \mathrm{~mm}$ apical extension of root canal filling showed statistically significantly higher mean $\%$ decrease in lesion volume than $2 \mathrm{~mm}$ apical extension of root canal filling after 3, 6 as well as 9 months (Figure 2,3).

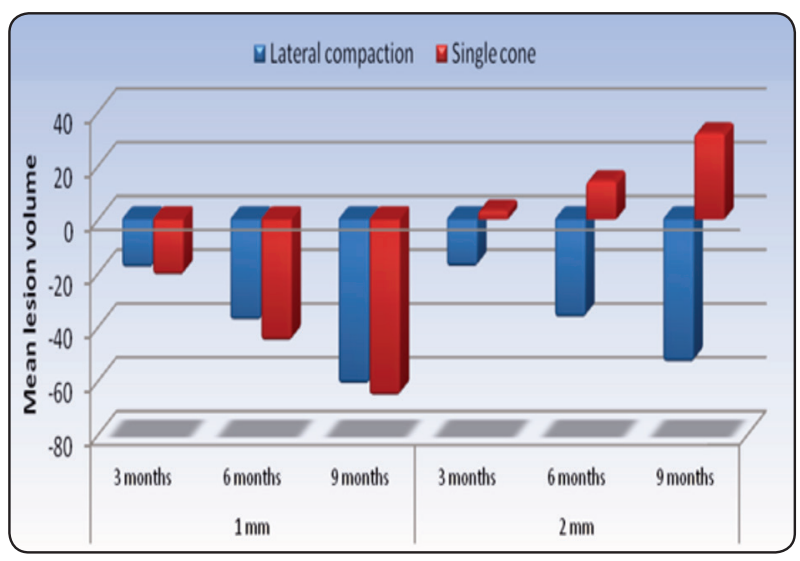

Fig. (2) Bar chart representing comparison between mean \% changes in lesion volumes using lateral compaction and single cone obturation techniques in symptomatic cases

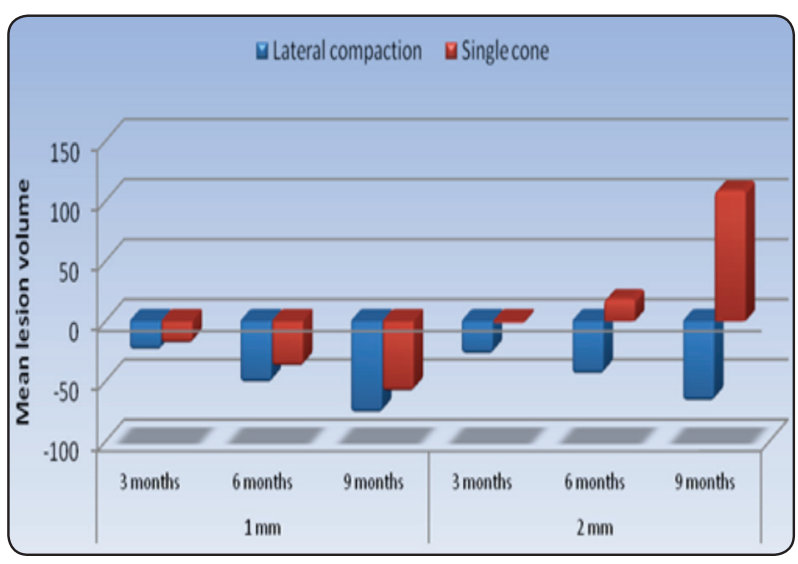

Fig. (3) Bar chart representing comparison between mean \% changes in lesion volumes using lateral compaction and single cone obturation techniques in asymptomatic cases 


\section{DISCUSSION}

According to the results of this study, obturation technique was not a factor affecting the healing process of both symptomatic and asymptomatic cases with $1 \mathrm{~mm}$ apical extension of filling. As there was no statistically significant difference regarding mean $\%$ changes in lesion volume after using lateral compaction or single cone techniques through the whole study period. This is in consonance with many studies ${ }^{(7-9)}$ which reported no significance influence of the effect of root filling materials/ techniques on treatment outcome. In addition, many studies $\left({ }^{10,11)}\right.$ documented that single-cone technique with a suitable resin-based sealer can achieve the same success rates of other obturation techniques as thermoplasticized or cold lateral compaction obturation techniques. On the other hand; at $2 \mathrm{~mm}$ apical extent, lateral compaction technique revealed higher mean \% decrease in lesion volume than single cone technique. Also, Van Nieuwenhuysen et al. ${ }^{(12)}$ found that the use of lateral compaction technique was associated with significantly higher success rate than the use of a single cone technique. This might be due to; in root canals with preoperative periapical lesions require thorough disinfection especially apically which always has lateral and accessory root canals and ramifications. So, periapical healing might be hindered if the obturating materials were not well condensed and terminated close to the apical foramen ${ }^{(13)}$. Other studies revealed that more leakage may occur due to the reduced gutta-percha/sealer ratio while using single-cone obturation technique ${ }^{(14,15)}$. In contrary, a recently published study by Krug et al. ${ }^{(16)}$ Stated that obturation using matching-taper single-cone technique after adequate rotary instrumentation was more effective than lateral compaction technique after manual preparation technique. Regarding the apical extent of root canal filling, single cone technique, whether being symptomatic or asymptomatic cases obturated at $1 \mathrm{~mm}$ apical extension of filling showed higher mean $\%$ decrease in lesion volume than $2 \mathrm{~mm}$ after 3, 6 as well as
9 months. This is in accordance with other studies $^{(\mathbf{1 7}, 18)}$. Wu et al. ${ }^{(19)}$ reported that single cone technique has high volume of sealer that accumulates in the apical $2 \mathrm{~mm}$ and will dissolute later on; consequently, long term treatment will be adversely affected ${ }^{(20,21)}$. Likewise, this outcome might be due to the poor sealing with single-cone technique because it is not compressed, but only inserted into the working length with a large amount of sealer and its dissolution permits ingress of inflammatory products lead to reinfection ${ }^{(22)}$. Difference in the healing outcome between symptomatic and asymptomatic cases obturated at $1 \mathrm{~mm}$ regardless of obturation technique were noticed after nine months, where there was some evidence indicating better healing outcomes for those asymptomatic than symptomatic. This might be inferred to the fact that pre-operative signs and symptoms may be a reflection of the microbial types and numbers in the root canal system that require much time for complete healing ${ }^{(15)}$. Nevertheless, other studies clarified that the healing rate of periapical lesion for teeth presenting with preoperative symptoms was comparable for asymptomatic teeth ${ }^{(22,23,24)}$. They reported that the healing process was directly related with the successful control of infection through root canal preparation and irrigation and proper debridement as well as obturation of the root canal ${ }^{(25,26)}$. However, even with the obtained results from the current study, the question still remains whether the obturation technique, apical extent of root canal filling, being symptomatic or asymptomatic, size of the periapical lesion, tooth type, quality of coronal restoration, medical status of the patient, intraoperative factors only the responsible factors involved in success/failure of root canal treatment. But still there is a constant search in dental biomaterials in an attempt to find an instrument, material or technique which can provide an efficient seal of the root canals, give chance for periapical healing, maintain tooth survival without signs symptoms and can be able to maintain that seal for long periods in the difficult oral conditions. 


\section{CONCLUSIONS}

Within the limitations of this study, the following conclusions can be deduced:

1. Short term radiographic outcome of single cone technique was comparable to those of lateral compaction technique in cases with periapical lesions obturated $1 \mathrm{~mm}$ from the radiographic apex.

2. Healing time was directly proportional with the volume of the lesion

3. CBCT provided a precise quantitative volumetric measurement of the periapical lesion to monitor the healing outcome.

4. Nine months evaluation period seems to be a predictor for the final outcome of primary root canal treatment in teeth with periapical lesions.

\section{REFERENCES}

1. Nair PN. Pathogenesis of apical periodontitis and the causes of endodontic failures. Crit Rev Oral Biol Med 2004; 15:348-81.

2. Card SJ, Sigurdsson A, Orstavik D and Trope M. The effectiveness of increased apical enlargement in reducing intracanal bacteria. J Endod 2002; 28:779-783.

3. Wang CY and Stashenko P. Characterization of boneresorbing activity in human periapical lesions. J Endod 1993; 19:107-111.

4. Cohen S and Burns RC. Pathway of the pulp 4th Ed. St. Louis: CV Mosby Co. 1987; 183-194.

5. Chisnoiu RM, Ovidiu P, Ada D, Petre D, Chisnoiu MP and Andrea MC. Clinical and radiological assessment of periapical wound healing of endodontically treated teeth using two different root canal filling materials. Aquac Aquar Conserv Legis 2016; 8:65-70

6. Bystrom A and Sundqvist G. Bacteriologic evaluation of the efficacy of mechanical root instrumentation in endodontic therapy. Scand J Dent Res 1981; 89:321-328.

7. Ricucci D, Siqueira JF Jr, Bate AL and Pitt Ford TR. Histologic investigation of root canal-treated teeth with apical periodontitis: a retrospective study from twentyfour patients. J Endod 2009; 35:493-502.

8. Nelson JA. Endodontics in general practice: a retrospective study. Int Endod J 1982: 15: 168-172.
9. Morse DR, Esposito JV, Pike C and Furst ML. A radiographic evaluation of the periapical status of teeth treated by the gutta-percha - eucapherca endodontic method. A one-year follow-up study of 458 root canals. Oral Surg Oral Med Oral Pathol 1983: 56:190-197.

10. Smith CS, Setchell DJ and Harty FJ. Factors influencing the success of conventional root canal therapy ${ }^{\text {a }}$ a five-year retrospective study. Int Endod J 1993: 26: 321-333.

11. Orstavik D and Horsted-Bindslev P. A comparison of endodontic treatment results at two dental schools. Int Endod J 1993; 26:348-354.

12. Van Nieuwenhuysen JP, Aouar M and DHoore W. Retreatment or radiographic monitoring in endodontics. Int Endod J 1994; 27:75-81.

13. Wu MK and Wesselink PR. A primary observation on the preparation and obturation of oval canals. Int Endod 2001; 34:137-141.

14. Schaeffer MA, White RR and Walton RE. Determining the optimal obturation length: a meta-analysis of literature. J Endod 2005; 31:271-274.

15. Cheng L, Zhang R, Yu X, Tian Y, Wang H, Zheng G and Hu T. A comparative analysis of periapical radiography and cone-beam computerized tomography for the evaluation of endodontic obturation length. Oral Surg Oral Med Oral Pathol Oral Radiol Endod 2011; 112:383-389.

16. Liang YH, Gang Li, Hagay S, Paul R, Wesselink and MinKai Wu. The association between complete absence of post-treatment periapical lesion and quality of root canal filling. Clin Oral Invest 2012; 16:1619-1626.

17. Alothmani OS, Friedlander LT and Chandler NP. Radiographic assessment of endodontic working length. Saudi Endo J: 2013; 3: 57-64.

18. Economides N, Kokorikos I, Kolokouris I, Panagiotis B and Gogos C. Comparative study of apical sealing ability of a new resin-based root canal sealer. J Endod 2004; 30:403-405.

19. Whitworth J. Methods of filling root canals: principles and practices. Endod Topics 2005; 12:2-24.

20. Zhao LQ and Xu XY. Influence of root canal working length on the clinical effect evaluated by periapical radiography and cone-beam computed tomography. Shanghai Kou Qiang Yi Xue 2014; 23:708-712.

21. IMC Wiki. Determination of length of obturation. International Medical College 2018; Full text available on http:// www.med-college.de/en/wiki/artikel.php?id=464. 
22. Deutsch AS. Root canal treatment: Where does the apex end? Dentistry IQ blog; Full text available on http://www. dentistryiq.com/articles/2017/01/root-canal-treatmentwhere-does-the-apex-end.

23. Harty FJ, Parkins BJ and Wengraf AM. Success rate in root canal therapy. A retrospective study on conventional cases. Br Dent J 1970; 128:65-70.
24. Heling B and Tamshe A. Evaluation of the success of endodontically treated teeth. Oral Surg Oral Med Oral Pathol 1970: 30: 533-536.

25. Adenubi JO. Rule DC. Success rate for root fillings in young patients. Br Dent J 1976: 141: 237-241.

26. Heling B and Shapira J. Roentgenologic and clinical evaluation of endodontically treated teeth, with or without negative culture. Quintessence Int 1978: 11: 79-84. 